www.jmscr.igmpublication.org

Impact Factor (SJIF): 6.379

Index Copernicus Value: 79.54

ISSN (e)-2347-176x ISSN (p) 2455-0450

crossrefDOI: https://dx.doi.org/10.18535/jmscr/v6i10.206

Journal Of Medical Science And Clinical Research

\title{
A Study of Refractive Errors in Pseudophakia
}

Authors

\section{A. Sumathi ${ }^{1}$, P.Mishra ${ }^{2}$, S. Manavalan ${ }^{3}$, V. Sridevi ${ }^{4}$, M. Ramya ${ }^{5}$}

Department of Ophthalmology, Rajah Muthiah Medical College, Annamalai University

Corresponding Author

Dr P. Mishra M.S. (Ophth), PhD (Ophth)

Head of the Department, Department of Ophthalmology, Rajah Muthiah Medical College,

Annamalai University

\begin{abstract}
Background: Cataract is the most prevalent, treatable cause of visual impairment and blindness in the world. Cataract surgery with an intraocular lens (IOL) implant is one of the most common and thought to be the most effective surgical procedure in any field of medicine. Very few studies had documented the refractive error in a pseudophaki patients.

Objectives: To find out the pattern of refractive error among the pseudophakic patients.

Material and Methods: Its descriptive hospital based study done among 100 psudophakic patients attending the department of ophthalmology 6 weeks after the cataract surgery between Oct 2017 and Oct 2018.

Results: $80 \%$ of the study participants were between 60 to 80 years. $51 \%$ of the study participants were males. $81 \%$ had undergone Manual SICS and 24\% had uncorrected visual acuity of 6/18, 22\% had 6/12 and 21\% had 6/9. Residual spherical refractive error in pseudophakics ranges from -3 to 1 DSP. Most of the study particpants' spherical refractive error falls between -0.5 to +0.5 (84\%). Post-Operative near Vision Accommodation needs to be corrected with +2.5 for monofocal IOLS. The residual post-operative astigamatism was more frequently an against-the-rule Astigmatism, ie, -0.5 to -1.00 at 90 DCP.

Conclusion: The psududophakic patients using monofocal IOLs and undergoing manual small incision cataract surgery are having less refractive correction and Against the rule astigmatism is produced due to corneo scleral scarring. The near vision correction is to be done for all the patients who are using monofocal IOLs.

Keywords: Pseudophakia, refractive error, astigmatism.
\end{abstract}

\section{Introduction}

Globally, the leading overall cause of blindness was cataract, followed by uncorrected refractive error; uncorrected refractive error was the leading global cause of moderate to severe visual impairment, followed by cataract ${ }^{(1)}$. A cataract is a clouding of the crystalline lens inside the eye, which leads to a decrease in vision ${ }^{(2)}$. The human crystalline lens is an encapsulated bag of transparent sequestered proteins. Changes in the arrangement and alterations in the character of the lens proteins result first in increasing rigidity of the lens, and eventual loss of transparency ${ }^{(1)}$.

Cataract is the most prevalent, treatable cause of visual impairment and blindness in the world. Cataract surgery with an intraocular lens (IOL) 
implant is one of the most common and thought to be the most effective surgical procedure inany field of medicine ${ }^{(2)}$. Over the past 10 years, advances in surgical equipment, techniques, and intraocular lens (IOL) design have enabled cataract surgery to evolve towards day case, small incision, suture less, phacoemulsification surgery with foldable lens implantation under local anaesthesia $^{(3)}$. Deteriorating visual function because of cataract requires restoration of the transparency of the optical pathway through replacement of the clouded crystal- line lens with an IOL with appropriate refractive power. All the above improvements had made cataract surgery both a replacement and refractive correction surgery $^{(1)}$

Growing concern exists over the outcomes of cataract surgery in the developing world. Recent population-based surveys have found that $40-75 \%$ of postoperative eyes have a presenting VA of worse than $6 / 18$, with as many as $50 \%$ worse than 6/60.8-11 Fewer surveys have measured outcomes based on best- corrected VA, however, several have reported up to $20 \%$ of eyes with corrected VA of, $6 / 60^{(4)}$. Very few studies had documented the refractive error in a pseudophakic patients. The objective of the present study was to find out the pattern of refractive error among the pseudophakic patients.

\section{Materials and Methods}

This was a hospital based descriptive study carried out in the department of ophthalmology, Rajah Muthiah Medical College and Hospital, Annamalai University, Chidambaram. The study was carried out among the patients who had attended the out-patient department of ophthalmology. The inclusion criteria was that the patient should undergone cataract surgery in any one eye. The exclusion criteria were complications during cataract surgery, any preexisting ocular pathology, Nd-yag capsulotomy and psychiatric abnormalities. The ethical approval for the above study was obtained from the institutional ethics committee. The study period was October 2017 to October 2018.

The data collection was done using a prestructured interview schedule, The unaided visual acuity was measured using Snellen's chart. The near vision was recorded at a distance of $33 \mathrm{~cm}$ using the Faculty's Roman test type notation chart. Keratometry was done manually (Boush and Lomb Keratometer). The astigmatism was defined as against the rule (ATR) if the steepest meridian was at $180^{\circ}+15^{\circ}$ i.e. a concave lens correction is given at $90 \mathrm{o}$ or concave lens is used at $180^{\circ}$. With the rule astigmatism (WTR) is defined when the steepest meridian is at $90^{\circ}+15^{\circ}$ correction of which is giving concave lens at $180 \mathrm{o}$ and concave lens at $90^{\circ}$ oblique astigmatism is when steepest meridian lies between $45^{\circ} / 150^{\circ}+$ $30^{\circ}$. The biometric values axial length is measured using the A-scan ultrasonography (contact or immersion) method mechanical waves is used to calculate the time needed for the pulse to travel from cornea to the retina.

The data collected were entered into Microsoft excel spread sheet and analysed using SPSS version 21. Descriptive statistics were used for the analysis.

\section{Results}

$80 \%$ of the study participants were between 60 to 80 years. $51 \%$ of the study participants were males (Table 1). $81 \%$ had undergone Manual SICS and $24 \%$ had uncorrected visual acuity of $6 / 18,22 \%$ had $6 / 12$ and $21 \%$ had 6/9(Table 2).

Table 1: Sociodemographic characteristic of the study participants

\begin{tabular}{|c|c|c|c|}
\hline \multicolumn{2}{|c|}{ Variable } & Frequency & Percentage \\
\hline \multirow{3}{*}{$\begin{array}{c}\text { Age group } \\
\text { (in years) }\end{array}$} & $\leq 60$ & 33 & 33 \\
\cline { 2 - 4 } & $61-70$ & 47 & 47 \\
\cline { 2 - 4 } & $71-80$ & 14 & 14 \\
\cline { 2 - 4 } & $>80$ & 6 & 6 \\
\hline \multirow{2}{*}{ Sex } & Male & 51 & 51 \\
\cline { 2 - 4 } & Female & 49 & 49 \\
\hline \multicolumn{2}{|c|}{ Total } & 100 & 100 \\
\hline
\end{tabular}


Table 2: Type of surgery and visual acuity before subjective correction.

\begin{tabular}{|c|c|c|c|}
\hline \multicolumn{2}{|c|}{ Variables } & Frequency & Percentage \\
\hline \multirow[t]{2}{*}{$\begin{array}{c}\text { Type of cataract } \\
\text { surgery }\end{array}$} & $\begin{array}{l}\text { Manual } \\
\text { SICS }\end{array}$ & 81 & 81 \\
\hline & $\begin{array}{l}\text { Phacoemul } \\
\text { sification. }\end{array}$ & 19 & 19 \\
\hline \multirow{7}{*}{$\begin{array}{l}\text { Visual acuity } \\
\text { Before subjective } \\
\text { correction. }\end{array}$} & $6 / 6$ & 2 & 2 \\
\hline & $6 / 9$ & 21 & 21 \\
\hline & $6 / 12$ & 22 & 22 \\
\hline & $6 / 18$ & 24 & 24 \\
\hline & $6 / 24$ & 16 & 16 \\
\hline & $6 / 36$ & 11 & 11 \\
\hline & $6 / 60$ & 4 & 4 \\
\hline \multicolumn{2}{|l|}{ Total } & 100 & 100 \\
\hline
\end{tabular}

Residual spherical refractive error in pseudophakics ranges from -3 to 1 DSP. Most of the study particpants' spherical refractive error falls between -0.5 to +0.5 (84\%). Post-Operative near Vision Accommodation needs to be corrected with +2.5 for monofocal IOLS. The residual postoperative a stigamatism was more frequently an against-the-rule Astigmatism, ie, -0.5 to -1.00 at 90 DCP (Table 3).

\begin{tabular}{|c|c|c|c|}
\hline \multicolumn{2}{|c|}{ Variable } & Frequency & Percentage \\
\hline \multirow[t]{7}{*}{ DSP } & -3 & 1 & 1 \\
\hline & -2 & 1 & 1 \\
\hline & -1 & 9 & 9 \\
\hline & -0.5 & 10 & 10 \\
\hline & 0 & 61 & 61 \\
\hline & 0.5 & 13 & 13 \\
\hline & 1 & 5 & 5 \\
\hline \multirow[t]{17}{*}{ DCP } & -0.0 T 9 & 1 & 1.0 \\
\hline & $-0.5 \mathrm{AT}$ & 7 & 7.0 \\
\hline & $-0.5 \mathrm{DCP}$ & 21 & 21.0 \\
\hline & -1 AT 90 & 3 & 3.0 \\
\hline & -1 AT90 & 1 & 1.0 \\
\hline & $-1 \mathrm{DCP} A$ & 12 & 12.0 \\
\hline & -1.00 at & 1 & 1.0 \\
\hline & $-1.00 \mathrm{AT}$ & 2 & 2.0 \\
\hline & $-1.00 \mathrm{DC}$ & 19 & 19.0 \\
\hline & $-1.5 \mathrm{AT}$ & 2 & 2.0 \\
\hline & $-1.5 \mathrm{DCP}$ & 17 & 17.0 \\
\hline & -2 AT 90 & 1 & 1.0 \\
\hline & $-2 \mathrm{DC}$ AT & 1 & 1.0 \\
\hline & -2 DCP A & 5 & 5.0 \\
\hline & $-2.00 \mathrm{DC}$ & 6 & 6.0 \\
\hline & $0.5 \mathrm{DCP}$ & 1 & 1.0 \\
\hline & Total & 100 & 100.0 \\
\hline
\end{tabular}

\section{Discussion}

This was a hospital based descriptive study carried out in the department of ophthalmology, Rajah Muthiah Medical College, Annamalai University between October 2017 and October 2018. Ethical approval was obtained from the institute ethical committee. The study participants included those patients who had undergone cataract surgery before 6 weeks from the date of recruitment of that particular patient. Patients who had complications during cataract surgery, who have pre-existing ocular pathology like uveitis, glaucoma, ARMD, diabetic retinopathy, corneal opacity, patient who had undergone Nd-Yag capsulotomy, Patient having psychotic abnormalities, systemic during like diabetic and autoimmune were excluded from the study. Informed consent was obtained from all the study participants enrolled into the study.

\section{Socio-Demographic Characteristics}

100 study participants with pseudophakic eye was enrolled into the study. $47 \%$ of the study participants were in the age - group of 61 to 70 years followed by less than 60 years (33\%). Cataract is usually the disease of the old age. $51 \%$ of the study participants were males. In contrast to the present study where males and females are almost equality et al reported that females were more than males in their study ${ }^{(3)}$.

\section{Surgery Characteristics}

$81 \%$ of the study participants had undergone manual SICS followed by $19 \%$ who had undergone phacoemulsification. Bourne et al reported that $61 \%$ of their study participants had undergone intra-capsular cataract extraction and $34 \%$ extra capsular cataract extraction ${ }^{(4)}$.

\section{Examination of Pseudophakic Eye}

Residual spherical refractive error in pseudophakics ranges from -3 to 1 DSP. Most of the study particpants' spherical refractive error falls between -0.5 to $+0.5(84 \%)$. Filey $\mathrm{R}$ et al reported that $90 \%$ achieved at least $6 / 12$ BSCVA post-surgery and $1.5 \%$ eyes exhibited a reduction in BSCVA post operatively ${ }^{(3)}$. Lau J reported that in the operated eye, $59.6 \%$ of the study participants presented with visual acuity $6 / 18$ or better. $11.2 \%$ of the opened eye were blind with vision less than $6 / 60^{(5)}$. Farmer et al reported that at day 1 postoperatively, $52.1 \%$ of the patients had 
a good outcome by World Health Organisation Criteria (unaided $V A \geq 6 / 18$ ). The same study also reported that Six months or later postoperatively, $85 \%$ of the eyes had best corrected $\mathrm{VA} \geq 6 / 18$ and $5.6 \%$ of the eyes had best-corrected $\mathrm{VA}<3 / 60$. The study also reported that mean post-operative spherical equivalent refraction was $-2.35 \pm 1.75$ dioptres ${ }^{(6)}$.

The residual post-operative astigamatism was more frequently an against-the-rule Astigmatism, ie, -0.5 to -1.00 at $90 \mathrm{DCP}$. Alio J et al reported that the vectorial astigmatic changes when MICS was done was $\leq 0.25$ dioptres in $35 \%$ of the eyes, $0.25 \mathrm{D}$ and $0.5 \mathrm{D}$ in $15 \%$ of the eyes and 0.5 to 1.0 $\mathrm{D}$ in $15 \%$ of the eyes. The mean vectorial astigmatic changes were $0.36 \pm 0.23 \mathrm{D}$ in the MICS group and $1.2 \pm 1.74 \mathrm{D}$ in the coaxial phacoemulsification group $^{(7)}$. Zhao in his study reported that $31.1 \%$ had presented postoperatively with VA of $20 / 32$ or better, $15.4 \%$ presented with VA of $20 / 40$ to $20 / 63,30.0 \%$ had presented VA worse than $20 / 63$ to $20 / 200$ and $23.5 \%$ had presented with VA worse than $20 / 200^{(8)}$. Zhao $\mathrm{J}$ in another study reported that out of the 87 individuals operated on for cataract, $12 \%(10 / 87)$ had presenting visual acuity of $6 / 18$ or more in both eyes and $24.1 \%(21 / 87)$ had less than $6 / 60$. Twenty-five percent (29/116) of the 116 eyes operated on for cataract had presenting visual acuity of $6 / 18$ or more, and $44.8 \%$ (52/116) had less than $6 / 60^{(9)}$.

Post-Operative near Vision Accommodation needs to be corrected with +2.5 for monofocal IOLS. Shah $\mathrm{S}$ et al in his study where he compare the miultifocal and the monofocal group reported that when the multifocal group $(\mathrm{n}=108)$ was compared with the monofocal group $(n=100)$, significantly more patients achieved uncorrected distance and near acuity of $0.1 \log$ MAR or better $(45.7 \%$ vs $2.1 \% ; \mathrm{P}<.0001)$ and spectacle independence $(73.3 \%$ vs $25.3 \% ; \mathrm{P}<.0001)$ at 6 months. The percentage of patients who achieved uncorrected distance visual acuity of 20/40 or better at 6 months was $92 \%$ in the multifocal group and $97 \%$ in the monofocal group ${ }^{(10)}$. This study shows that the distance vision us $6 / 12$ or better after correction and near vision $\mathrm{N}_{6}$ with correction after 6 month of post operator period using monofocal IOL.

The limitation for the study included were this is cross sectional study of the post-operative patients after 6 weeks were pre-operative evaluation is not included in the study. Monofocalrigid IOLs are mostly used by the patients who are included in the study so, all the patients required near vision correction.

\section{Conclusion}

The psududophakic patients using monofocal IOLs and undergoing manual small incision cataract surgery are having less refractive correction and Against the rule astigmatism is produced due to corneo scleral scarring. The near vision correction is to be done for all the patients who are using monofocal IOLs.

\section{Reference}

1. Lam D, Rao SK, Ratra V, Liu Y, Mitchell $\mathrm{P}$, King $\mathrm{J}$, et al. Cataract. Nat Rev Dis Prim. 2015; (June).

2. Thompson J, Lakhani N. Cataracts. Prim Care - Clin Off Pract. 2015;42(3):409-23.

3. Riley AF, Malik TY, Grupcheva CN, Fisk MJ, Craig JP, McGhee CN. The Auckland cataract study: Co-morbidity, surgical techniques, and clinical outcomes a public hospital service. $\mathrm{Br} \mathrm{J}$ Ophthalmol. 2002;86(2):185-90.

4. Bourne R, Dineen B, Jadoon Z, Lee PS, Khan A, Johnson GJ, et al. Outcomes of cataract surgery in Pakistan: Results from the Pakistan National Blindness and Visual Impairment Survey. $\mathrm{Br} \mathrm{J}$ Ophthalmol. 2007;91(4):420-6.

5. Lau J. Visual acuity and quality of life outcomes in cataract surgery patients in Hong Kong. Br J Ophthalmol [Internet]. 2002;86(1):12-7. Available from: http://bjo.bmj.com/cgi/doi/10.1136/bjo.86. 1.12 
6. Farmer L, Innes-Wong C, Bergman-Hart C, Casson RJ, Crompton J. Visual Acuity, Quality of Life and Visual Function Outcomes after Cataract Surgery in Bali. Ophthalmic Epidemiol. 2015;22(4):27482.

7. Alió J, Rodríguez-Prats JL, Galal A, Ramzy M. Outcomes of microincision cataract surgery versus coaxial phacoemulsification. Ophthalmology. 2005;112(11):1997-2003.

8. Zhao J, Ellwein LB, Cui H, Ge J, Guan H, Lv J, et al. Prevalence and outcomes of cataract surgery in rural China: The China nine-province survey. Ophthalmology [Internet]. 2010;117(11):2120-8. Available from: http://dx.doi.org/10.1016/j.ophtha.2010.03. 005

9. He M, Xu J, Li S, Wu K, Munoz SR, Ellwein LB. Visual acuity and quality of life in patients with cataract in Doumen County, China. Ophthalmology. 1999;106(8):1609-15.

10. Shah S, Peris-Martinez C, Reinhard T, Vinciguerra P. Visual Outcomes After Cataract Surgery: Multifocal Versus Monofocal Intraocular Lenses. J Refract Surg [Internet]. 2015;31(10):658-66. Available from: http://www.healio.com/doiresolver?doi=10 .3928/1081597X-20150611-01 